\title{
Gaining of common culture perception to students in divided societies and the role of Art course in this context; Northern and Southern Cyprus
}

\author{
Fatma Miralay ${ }^{1, *}$ \\ ${ }^{1}$ Near East University Atatürk Faculty of Education, North Cyprus Boulevard, 88138 Nicosia \\ TRNC Mersin 10 - Turkey.
}

\begin{abstract}
Cultural dimension in education bears importance in terms of transferring and sustaining cultural values in addition to creating local and upper intercultural awareness in individuals. Especially in divided societies, gaining cultural values to individuals via education eliminates boundaries between societies, ensures cultural integration and carries local values to a universal point without terminating them. In this paper, effort is paid to identify the importance of preserving common cultural values of Cyprus in the content of art course curricula applied in Northern and Southern Cyprus societies according to teacher opinions. In accordance with this purpose, research data were collected using a semi-structured interview form which is a qualitative research method. The study was conducted on 20 secondary education art teachers in capital Northern and Southern Nicosia regions. Descriptive analysis method was used in the analysis of data. An examination of research results shows that there is no difference between the opinions of Turkish Cypriot and Greek Cypriot teachers, but that Turkish Cypriot teachers give more prominence to the basic needs as regards the course. It has been determined that material needs of Greek Cypriot teachers are supported by the ministry whereas the opportunities of Turkish Cypriot teachers are limited. A majority of the teachers emphasized that the topic should be included in education curricula and the methods should serve to put this into practice. In the study, it has been concluded that the similarity of positive opinions between Turkish Cypriot and Greek Cypriot teachers is high and that there are fewer disagreements.
\end{abstract}

\footnotetext{
* Corresponding author: fatma.miralay@neu.edu.tr
} 


\section{Introduction}

Rapid changes in the globalizing world affect human life and bring about changes in education systems. This, in turn, creates the need for renovating and structuring of education; it must also respond to the future-oriented needs of societies. Education, which plays an essential role in the planning of futures of societies and individuals, is determinant on their cultural development [8]. It is known that the dimension of culture in education is included in different education curricula starting from preschool period [7]. Education curricula which also equip individuals with cultural acquisitions make contribution to provide them with high-level development, reinforcement of values at local dimensions, compromising skills and formation of a sense of belonging [11]. It is also known that in the last decade UNESCO has been organizing several workshops on equipping students with cultural transfer and determining short-term and long-term objectives in the field of education and culture. In these studies, the functionality of art and the harmony between contents in cultural affairs has been displayed. In addition, a call has been made to take immediate action in education so that the lost cultural values could be regained and cultural awareness could be created [15]. Art education, which is an essential part of the cultural entirety in education, attracts attention with the function of gaining individuals local and different intercultural relations and stands out among other disciplines with this feature [6]. Art education, which is the cornerstone of contemporary education process, displays the necessity of art education programs regardless of racial, class and gender differences. Maziere [9] claimed that visual arts course, which was a part of education curricula depending on art education, assumed the role of creating a common language in European countries in addition to aesthetic acquisitions. Cabedo-Mas et al. [5] believed that gaining cultural values to individuals in societies with education could eliminate boundaries between societies, realize economic and cultural integration and create a universal culture without terminating local values. Miralay [10] conducted a similar study and argued that especially in societies which experienced conflicts, comparative arts education studies could create solution-oriented alternative visions to societies. In the light of such information, covering the topic of common cultural values in Northern and Southern Cyprus within the framework of art education curricula and evaluating based on teacher opinions is seen as a topic worth studying. Within this scope, below are the sub-problems of the study:

1. What are the opinions of art teachers in Northern Cyprus concerning the common cultural values of Cyprus?

2. What are the opinions of art teachers in Southern Cyprus concerning the common cultural values of Cyprus?

3. Are there any similarities and differences between the opinions of art teachers working in both societies?

\section{Method}

The purpose of this study is to evaluate the common cultural values of Cyprus in the content of art course curricula offered in Northern and Southern Cyprus based on 
teacher opinions. Within this objective, "interview technique" which is a qualitative research method has been used in this study.

\subsection{Study Group}

The sample of the study consists of secondary school teachers in Northern and Southern Nicosia. Convenience sampling, which is a purposive sampling method, has been used in determining the participants. Two schools (Secondary schools A and B) and 10 art course teachers in Southern Nicosia region and 2 secondary schools (Secondary schools C and D) and 10 art course teachers in Northern Nicosia region constituted the study group of the study. A total of 20 art teachers serving at secondary stage were included in the study and demographic information on the teachers is provided in Table 1.

Table 1. Demographic Variables of Teachers

\begin{tabular}{|c|c|c|c|c|}
\hline & \multicolumn{2}{|c|}{ Turkish Cypriot Teachers } & \multicolumn{2}{|c|}{ Greek Cypriot Teachers } \\
\hline & f & $\%$ & $\mathbf{f}$ & $\%$ \\
\hline \multicolumn{5}{|l|}{ Gender } \\
\hline Male & 3 & $\% 30$ & 4 & $\% 40$ \\
\hline Female & 7 & $\% 70$ & 6 & $\% 60$ \\
\hline \multicolumn{5}{|l|}{ Age } \\
\hline $31-45$ & 2 & $\% 20$ & 4 & $\% 40$ \\
\hline $36-40$ & 3 & $\% 30$ & 1 & $\% 10$ \\
\hline $41-45$ & 5 & $\% 50$ & 3 & $\% 30$ \\
\hline \multicolumn{5}{|l|}{ Field of undergraduate study } \\
\hline Fine arts faculty & 7 & $\% 70$ & 8 & $\% 80$ \\
\hline Education faculty fine arts & 3 & $\% 30$ & 2 & $\% 20$ \\
\hline \multicolumn{5}{|l|}{ Education status } \\
\hline Undergraduate & 7 & $\% 70$ & 5 & $\% 50$ \\
\hline Master of Arts & 2 & $\% 20$ & 4 & $\% 40$ \\
\hline $\mathrm{PhD}$ & 1 & $\% 10$ & 1 & $\% 10$ \\
\hline \multicolumn{5}{|l|}{ Professional seniority } \\
\hline $1-5$ years & - & - & 1 & $\% 10$ \\
\hline $6-10$ years & 4 & $\% 40$ & 5 & $\% 50$ \\
\hline $11-15$ years & 3 & $\% 30$ & 3 & $\% 30$ \\
\hline $16-20$ years & 2 & $\% 20$ & - & \\
\hline 21 years and more & 1 & $\% 10$ & 1 & $\% 10$ \\
\hline \multicolumn{5}{|l|}{ Participation in artistic activities } \\
\hline $1-2$ a year & 2 & $\% 20$ & 3 & $\% 30$ \\
\hline $2-4$ & 3 & $\% 30$ & 5 & $\% 50$ \\
\hline 5 and more & - & - & 2 & $\% 20$ \\
\hline None & 5 & $\% 50$ & - & - \\
\hline Total & 10 & 100 & 10 & 100 \\
\hline
\end{tabular}


Table 1 provides information on the art teachers who work at secondary education institutions of both societies. Considering the genders of teachers, it is seen that the number of "female" teachers in both societies is higher. Considering the mean age values of teachers, it has been determined that in the north they are between 41 and 45 ages whereas in the south the age interval is 31 to 45 . An examination of the branch of teachers shows that teachers in both societies are graduates of fine arts faculties. Considering the education status of teachers shows that graduate education is widespread in both societies. An examination of professional seniority interval of teachers shows that they have between 6 and 10 years of experience in both north and south. Finally, an examination of the participation of teachers in artistic activities shows that teachers in the north do not participate in such activities whereas teachers in the south show participation for 2 to 4 times a year.

\subsection{Data collection tool}

In this study, a semi-structured interview form was prepared by the researcher with the purpose of determining the opinions of art course teachers. In order to write the question items, literature search was made first in the creation of question form stage and effort was paid to identify the present situation of curricula in both societies. Then expert opinion, reliability and scope validity stages were followed and the form was thus given its final form.

\subsection{Application}

In the application of the study, interviews were held with the managers of 4 secondary schools in northern and southern Nicosia regions and permission was obtained which was necessary for the application. Then, interviews were conducted with art teachers who worked at these schools and it was clearly stated that the application was based on voluntarism. Later, discussions were held with teachers who accepted to participate in the study and interviews were held between November 2017 and January 2018. In the application stage of the form, the researcher visited the schools and conducted face-to-face interviews with teachers and the opinions of teachers who permitted voice recording were recorded.

\subsection{Analysis of Data}

In order to find answer to the research question in the analysis of data, the interview data obtained from the interviews with study group members were analyzed with descriptive analysis method. In accordance with this objective, the basic framework of data analysis of the topic was prepared with the coding's based on interviews, research objectives and research questions. Based on these coding's, meaningful and logical categories and themes were formed. Tables were created based on each question in the interview form and findings were digitalized and the findings were presented in the form of frequencies. In order to distinguish the nationalities of teachers, they were coded as Turkish Cypriot teachers (T.C.T) and Greek Cypriot teachers (G.C.T). 


\section{Findings}

In this section, the findings obtained from the interview form applied to teachers are tabulated and presented below.

\subsection{Are there any activities in your school with the purpose of introducing the cultural values of Cyprus?}

Table 1. The opinions of Turkish Cypriot teachers concerning school activities aiming at teaching the common cultural values of Cyprus

\begin{tabular}{|l|l|c|}
\hline & Activities & $\boldsymbol{f}$ \\
\hline \multirow{4}{*}{ T.C.T } & The need for a curriculum & 10 \\
\cline { 2 - 3 } & The need for ministerial and school support & 9 \\
\cline { 2 - 3 } & Inadequate class hours & 8 \\
\cline { 2 - 3 } & Overcrowded classrooms & 5 \\
\cline { 2 - 3 } & Difference of topic & 2 \\
\cline { 2 - 3 } & Inadequate awareness as regards the topic & $\mathbf{3 5}$ \\
\hline Total & & 1 \\
\hline
\end{tabular}

Table 2. The opinions of Greek Cypriot teachers concerning school activities aiming at teaching the common cultural values of Cyprus

\begin{tabular}{|l|l|l|}
\hline & Activities & f \\
\hline \multirow{4}{*}{ G.C.T } & Regular competitions held by the ministry & 10 \\
\cline { 2 - 3 } & Increasing activities on the topic of common culture & 4 \\
\cline { 2 - 3 } & Financial support opportunities & 4 \\
\cline { 2 - 3 } & Regular workshop facilities & 3 \\
\hline Total & & 21 \\
\hline
\end{tabular}

An examination of table 1 shows that a majority of Turkish Cypriot teachers stated that, first and foremost, they did not have a curriculum $(\mathrm{f}=10)$. A group of teachers claimed that support from the ministry and the school for extra-school trips was negligible ( $\mathrm{f}=9$ ). In addition, they stated that class hours were short for this kind of trips $(\mathrm{f}=8)$, that classrooms were overcrowded $(\mathrm{f}=5)$ and that course topics were not consistent with this type of activities $(\mathrm{f}=2)$. One of the teachers emphasized that the school management and the ministry was not sensitive towards this topic $(\mathrm{f}=1)$. An examination of Table 2 shows that a majority of Greek Cypriot teachers are satisfied with the ministerial support $(\mathrm{f}=19=$ but that they complain that common cultural topics are not given adequate place in activities $(\mathrm{f}=4)$. A group of teachers expressed that they received financial support from the ministry $(\mathrm{f}=4)$ as a result of which they could organize activities at the school $(\mathrm{f}=3)$.

\subsection{Are there any topics directed towards recognizing the common cultural values of Cyprus in the content of the curriculum that you implemented?}

Table 3. Opinions of Turkish Cypriot teachers on the inclusion of common cultural values of Cyprus in the curriculum of art course.

\begin{tabular}{|l|l|c|}
\hline & Program content & $\boldsymbol{f}$ \\
\hline \multirow{4}{*}{ T.C.T } & Program deficiency & 9 \\
\cline { 2 - 3 } & The importance of improvement and diversification of program & 7 \\
\cline { 2 - 3 } & Including extra-curriculum topics as regards cultural values & 7 \\
\cline { 2 - 3 } & The need for conducting cultural-based learning outside school & 5 \\
\cline { 2 - 3 } & Redesigning the content of program according to teacher opinions & 3 \\
\cline { 2 - 3 } & Redesigning the content of program according to student needs & 1 \\
\hline Total & & $\mathbf{3 2}$ \\
\hline
\end{tabular}


Table 4. Opinions of Greek Cypriot teachers on the inclusion of common cultural values of Cyprus in the curriculum of art course.

\begin{tabular}{|l|l|c|}
\hline & Program content & $\boldsymbol{f}$ \\
\hline \multirow{4}{*}{ G.C.T } & The importance of giving more place to Cyprus culture in program content & 10 \\
\cline { 2 - 3 } & Supporting cultural topics with extra-school activities & 7 \\
\cline { 2 - 3 } & Teachers creating a suitable environment for the topic of culture & 3 \\
\cline { 2 - 3 } & The need for on-the-job training concerning the topic & 2 \\
\cline { 2 - 3 } & School management being more sensitive towards the topic & $\mathbf{2 3}$ \\
\hline Total & & \\
\hline
\end{tabular}

An examination of table 3 shows that most of Turkish Cypriot teachers stated that they did not have any program concerning visual arts course $(\mathrm{f}=9)$. A group of teachers, on the other hand, displayed that the topic should be included in the curriculum $(\mathrm{f}=7)$. It has been stated that extra-curriculum classes should be offered concerning common cultural values $(\mathrm{f}=7)$ and, as a result, teachers wanted to cover these topics outside school, too $(\mathrm{f}=5)$. Some teachers stated that the curriculum should be designed by specialized people after receiving the opinion of teachers $(\mathrm{f}=3)$. One teacher said that the curriculum should be designed after determining the needs of students $(\mathrm{f}=1)$. Table 4 shows that a majority of Greek Cypriot teachers displayed the importance of Cypriot common cultural values in the content of curriculum $(\mathrm{f}=10)$. In addition, a group of teachers stated that teaching cultural values should be performed based on extra-school activities $(f=7)$. Some teachers claimed that preparing a suitable environment for the topic in the class is the task of the teacher $(\mathrm{f}=3)$ whereas some others stated that they needed on-the-job training on the topic $(\mathrm{f}=2)$. One teacher argued that school management should be more sensitive towards such topics ( $\mathrm{f}=1)$.

\subsection{Do you organize extra-school trips so that the cultural values in our country can be learned by students?}

Table 5. The opinions of Turkish Cypriot teachers concerning extra-school trips in the curriculum process of art course.

\begin{tabular}{|l|l|c|}
\hline & Extra-school trip & $\boldsymbol{f}$ \\
\hline \multirow{4}{*}{ T.C.T } & Transportation problems & 10 \\
\cline { 2 - 3 } & Inadequate class hours & 9 \\
\cline { 2 - 3 } & The necessity to visit historical places & 8 \\
\cline { 2 - 3 } & Teaching the folkloric values of Cyprus in class environment & 7 \\
\cline { 2 - 3 } & The teacher creating opportunities with his/her own facilities & 5 \\
\cline { 2 - 3 } & Academic program-focused school management & 4 \\
\cline { 2 - 3 } & Overcrowded classrooms & 3 \\
\hline Total & & $\mathbf{7 4}$ \\
\hline
\end{tabular}

Table 6. The opinions of Greek Cypriot teachers concerning extra-school trips in the curriculum process of art course.

\begin{tabular}{|l|l|c|}
\hline & Extra-school trip & $\boldsymbol{f}$ \\
\hline G.C.T & Adequate transportation facilities & 7 \\
\hline & $\begin{array}{l}\text { Introducing to students the history and artists of Cyprus in extra-school } \\
\text { environments }\end{array}$ & 7 \\
\hline & Inadequacy of class hours & 3 \\
\hline & Intense academic program & 1 \\
\hline Total & Economic limitations & 1 \\
\hline
\end{tabular}


As can be seen in Table 5, a majority of Turkish Cypriot teachers complain that they do not conduct extra-school trips due to transportation problems $(\mathrm{f}=10)$ and that the length of class hours prevents organizing such trips $(f=9)$. A group of teachers emphasized the importance of visiting historical places $(f=8)$. Some teachers who cannot perform extra-school trips argued that folkloric values belonging to Cyprus could be transferred to the students in class environment $(\mathrm{f}=7)$ whereas some others claimed that academic-oriented curriculum imposed limitations on many topics $(\mathrm{f}=5)$. On the other hand, Table 6 shows that most Greek Cypriot teachers are satisfied with transportation opportunities $(\mathrm{f}=7)$ and that they have the opportunity of introducing to students the history and artists of Cyprus outside school $(\mathrm{f}=7)$. A group of teachers claimed that class hours were inadequate $(\mathrm{f}=3)$. Some teachers argued that teaching curricula were academic-oriented $(\mathrm{f}=1)$ and that there were economic restraints for extra-school trips $(\mathrm{f}=1)$.

\subsection{According to you, how important is the inclusion of common cultural values in visual arts course curriculum?}

Table 7. The opinions of Turkish Cypriot teachers on the importance of including common cultural values of Cyprus topic in art course curriculum.

\begin{tabular}{|l|l|c|}
\hline & Importance & $\boldsymbol{f}$ \\
\hline \multirow{4}{*}{ T.C.T } & Creating a contemporary and democratic student profile & 9 \\
\cline { 2 - 3 } & Contributing to the societies in knowing each other more closely & 8 \\
\cline { 2 - 3 } & Creating opportunities so that students can cover different topics & 8 \\
\cline { 2 - 3 } & Creating a student profile who is humanist and respectable to historical values & 7 \\
\cline { 2 - 3 } & Introducing to the society individuals which know cultural awareness & 6 \\
\hline Total & & $\mathbf{3 8}$ \\
\hline
\end{tabular}

Table 8. The opinions of Greek Cypriot teachers on the importance of including common cultural values of Cyprus topic in art course curriculum.

\begin{tabular}{|l|l|c|}
\hline & Importance & $\boldsymbol{F}$ \\
\hline \multirow{4}{*}{ G.C.T } & Individuals who know the culture of both societies & 10 \\
\cline { 2 - 3 } & Equipping the student with the awareness of history between both societies & 10 \\
\cline { 2 - 3 } & Making contribution to the development of humanist personality & 9 \\
\cline { 2 - 3 } & Creating an awareness for preserving cultural values & 3 \\
\cline { 2 - 3 } & Establishing affinity between societies & 2 \\
\hline Total & & $\mathbf{3 4}$ \\
\hline
\end{tabular}

An examination of Table 7 shows that a majority of Turkish Cypriot teachers believed that including this topic in teaching curriculum would create a contemporary and democratic student profile $(\mathrm{f}=9)$. A group of teachers stated that it would allow for the societies to know each other more closely $(\mathrm{f}=8)$. A different group of teachers argued that it would contribute the students to learn different cultural topics which were not included in course curriculum $(\mathrm{f}=8)$. Some teachers, on the other hand, claimed that students would gain a humanist personality and the ability to respect historical values $(\mathrm{f}=7)$. Some teachers stated that students with developed cultural awareness could be introduced to the society $(f=6)$. Table 8 provides the opinions of Greek Cypriot teachers such as they would be individuals who knew the culture of both societies $(\mathrm{f}=10)$. They also stated that an awareness of the history between two societies would be given to students $(\mathrm{f}=10)$. A group of teachers argued that it would contribute to the formation of a humanist culture in students $(f=9)$ whereas another group mentioned the awareness of preserving 
cultural values in students $(\mathrm{f}=3)$ and the opportunity of establishing an affinity between societies $(\mathrm{f}=2)$.

3.5 What is the extent of your knowledge about common cultural values in Northern and Southern Cyprus?

Table 9. Opinions of Turkish Cypriot teachers concerning their competencies on common cultural values of Cyprus.

\begin{tabular}{|l|l|c|}
\hline & Teacher competencies & $\boldsymbol{f}$ \\
\hline \multirow{3}{*}{ T.C.T } & Thinking that they have adequate knowledge & 10 \\
\cline { 2 - 3 } & The will for possessing more information & 7 \\
\cline { 2 - 3 } & Not finding necessary & 2 \\
\cline { 2 - 3 } Total & Thinking that it is parallel to course content & 1 \\
\hline
\end{tabular}

Table 10. Opinions of Greek Cypriot teachers concerning their competencies on common cultural values of Cyprus.

\begin{tabular}{|l|l|c|}
\hline & Teacher competencies & $\boldsymbol{f}$ \\
\hline \multirow{3}{*}{ G.C.T } & Thinking that they have adequate knowledge & 9 \\
\cline { 2 - 3 } & Relating to course curriculum & 5 \\
\cline { 2 - 3 } & Having very negligible knowledge & 1 \\
\cline { 2 - 3 } & Not finding necessary & 1 \\
\hline Total & & $\mathbf{1 6}$ \\
\hline
\end{tabular}

An examination of table 9 shows that a majority of Turkish Cypriot teachers think that they are adequately knowledgeable about common cultural values of Cyprus $(\mathrm{f}=10)$. A group of teachers, on the other hand, stated that they wanted to be more knowledgeable $(f=7)$. Another group of teachers believe that this knowledge is unnecessary $(\mathrm{f}=2)$. With a different viewpoint, another teacher expressed that the topic was not parallel to the course and knowledge was unnecessary at this point $(\mathrm{f}=1)$. Table 10 provides the opinions of Greek Cypriot teachers. Most of them think that they have adequate knowledge $(\mathrm{f}=9)$. A different group of teachers stated that they could not relate the topic with the course $(\mathrm{f}=5)$ and that they were not much knowledgeable $(\mathrm{f}=1)$. A teacher displayed a different viewpoint and argued that this knowledge was unnecessary $(\mathrm{f}=1)$.

\subsection{What kind of a generation will be created in the future if common cultural values of Cyprus are taught to art students?}

Table 11. Opinions of Cypriot Turkish teachers concerning the teaching of cultural values of Cyprus in visual arts class and their acquisitions.

\begin{tabular}{|l|l|c|}
\hline & Student profile & $\boldsymbol{f}$ \\
\hline \multirow{5}{*}{ T.C.T } & Pacifist individual & 10 \\
\cline { 2 - 3 } & Individual who respects cultural values & 9 \\
\cline { 2 - 3 } & $\begin{array}{l}\text { Constructive individual with developed personality skills who can produce } \\
\text { solution to problems }\end{array}$ & 9 \\
\cline { 2 - 3 } & Individual with humanist characteristics & 8 \\
\cline { 2 - 3 } & Individual who comprehends the importance of culture & 7 \\
\cline { 2 - 3 } & Finding unnecessary & 3 \\
\hline Total & & $\mathbf{5 0}$ \\
\hline
\end{tabular}


Table 12. Opinions of Greek Cypriot teachers concerning the teaching of cultural values of Cyprus in visual arts class and their acquisitions.

\begin{tabular}{|l|l|c|}
\hline & Student profile & $\boldsymbol{f}$ \\
\hline \multirow{5}{*}{ G.C.T } & Individual with strong sense of belonging & 8 \\
\cline { 2 - 3 } & Respectful and democratic individual with an awareness of human rights & 8 \\
\cline { 2 - 3 } & Individual who lays claim to his culture & 7 \\
\cline { 2 - 3 } & Intellectual individual who knows cultural features & 4 \\
\cline { 2 - 3 } & Contemporary individual who gained an awareness for peace & 4 \\
\cline { 2 - 3 } & Individual who is able to transfer his cultural heritage & 3 \\
\hline Total & & $\mathbf{5 3}$ \\
\hline
\end{tabular}

An examination of table 11 shows that a majority of Turkish Cypriot teachers believe that pacifist $(\mathrm{f}=10)$, respectful to cultural values $(\mathrm{f}=9)$, constructive individuals who can produce solution to problems $(\mathrm{f}=9)$ would be raised. Another group of teachers stated that they believed that individuals who haved humanist characteristics $(f=8)$ and comprehended the importance of culture $(f=7)$ would be raised. With a different viewpoint, a group of teachers expressed that they found this topic unnecessary $(\mathrm{f}=3)$. Table 12 shows that Greek Cypriot teachers generally believed that students with strong sense of belonging were raised $(f=8)$ and that respectful and democratic individuals with a sense of human rights would be raised $(\mathrm{f}=8)$. Another group of teachers stated that they believed that individuals who laid claim to their culture $(\mathrm{f}=7)$ and intellectual students who recognized the characteristics of their culture $(f=4)$ would be raised. Another group of teachers stated that they believed that contemporary individuals with a sense of peace $(\mathrm{f}=4)$ and able to transfer their cultural heritage would be raised $(\mathrm{f}=3)$.

\subsection{How sensitive are our students towards Cypriot common culture issues?}

Table 13. Opinions of Turkish Cypriot teachers on the sensitiveness of students towards Cypriot common cultural values

\begin{tabular}{|l|l|c|}
\hline & Student sensitiveness & $\boldsymbol{f}$ \\
\hline \multirow{4}{*}{ T.C.T } & Difference of the area of interest of students & 10 \\
\cline { 2 - 3 } & Differences based on family cultural structure of students & 9 \\
\cline { 2 - 3 } & Peer and community factor effects & 8 \\
\cline { 2 - 3 } & Teacher-based awareness-raising & 8 \\
\cline { 2 - 3 } & Low level of student sensitiveness & 6 \\
\cline { 2 - 3 } & Students suffering from expression issues & 5 \\
\cline { 2 - 3 } & Motivation by teacher & $\mathbf{6 6}$ \\
\hline Total & & 1 \\
\hline
\end{tabular}

Table 14. Opinions of Greek Cypriot teachers on the sensitiveness of students towards Cypriot common cultural values.

\begin{tabular}{|l|l|c|}
\hline & Student sensitiveness & $\boldsymbol{f}$ \\
\hline \multirow{5}{*}{ G.C.T } & Cultural differences & 10 \\
\cline { 2 - 3 } & Technology-based student profile & 9 \\
\cline { 2 - 3 } & Course content limitations & 8 \\
\cline { 2 - 3 } & Academic liabilities & 6 \\
\cline { 2 - 3 } & Importance of family factor & 4 \\
\cline { 2 - 3 } & Readiness level of student & 4 \\
\cline { 2 - 3 } & Differences in student objectives & 3 \\
\hline Total & & $\mathbf{4 5}$ \\
\hline
\end{tabular}


An examination of table 13 shows that a majority of Turkish Cypriot teachers mention the differences in the area of interest of students ( $f=9$ ), peer and community factor effects $(\mathrm{f}=8)$ and teacher-based awareness raising $(\mathrm{f}=8)$. A different group of teachers emphasized that students suffered from low sensitiveness $(\mathrm{f}=6)$ and expression issues $(\mathrm{f}=1)$ whereas one teacher claimed that an increase in this sensitiveness depended on motivation by teachers ( $\mathrm{f}=1)$. Table 14 shows that a majority of Greek Cypriot teachers mentioned cultural differences $(f=10)$, technology-oriented student profile $(f=9)$, course content limitations $(f=8)$ and academic liabilities $(\mathrm{f}=6)$. Another group of teachers emphasized the importance of family factor $(\mathrm{f}=4)$, student readiness level $(\mathrm{f}=4)$ and differences in student objectives $(\mathrm{f}=3)$.

\section{Discussion and Conclusion}

The results obtained from this study have revealed that the content of art course applied in northern and southern Cyprus does not include the topic of common culture. The research compared the opinions of Turkish Cypriot and Greek Cypriot teachers working in both societies and evaluated the content of the curricula in both societies as regards the topic based on teacher opinions. Within the scope of the questions asked to the teachers, it has been found out that there is not huge difference between the opinions of Turkish Cypriot and Greek Cypriot teachers but that the basic needs of Turkish Cypriot teachers concerning the course have more priority. For example, in the opinions of Turkish Cypriot teachers as regards whether any activities are performed concerning the topic, it was expressed that basic needs had priority. On the other hand, Greek Cypriot teachers emphasized that they did not have any problems as regards course-related needs but that the content of the course should be enriched. For example, Bellenge-Morris and Stuhr [3] concluded in their study that school activities were almost compulsory in drawing class which increased motivation in students and ensured permanence in their learning.

The answers given to another question of the study revealed that the content of the curricula applied in both societies lacked common culture topics but that positive opinions as regards the participation of teachers were very similar. Barkhordari et al. [2] studied the popularization of peace culture through art education and stated that including cultural phenomena especially in the contents of course curricula had positive effects on individuals. Teachers were also asked about their opinions on extra-school trips and visits to historical places in the application process of the course. The results obtained here make clear that there are differences in both societies. It has been found out that the material needs Greek Cypriot teachers are supported by the ministry and that Turkish Cypriot teachers have more limited opportunities. In addition, it has been determined that teachers in both societies have problems in terms of the length of lectures, academic curriculum and classroom size and that their opinions at this point are similar. For example, Akhmetov et al. [1] claim that extra-school trips and introduction of historical places to students at art classroom prevents loss of cultural heritage. A similar study by Şahin and Yağc1 [14] emphasized the importance of local cultural values in art classroom in the socialization process of individuals and concluded that students enjoyed integrity in knowledge by seeing what they draw. A similar conclusion reached in another question of the study is that teachers working in both societies think that including 
the topic of common culture in the program content is essential. Teachers especially emphasized the importance of course content in preserving local culture and establishing affinity between societies. Bianchi [4] explained that the formation of cultural identity in societies is intertwined with art education and emphasized that this fact should be related to the course content. In another question, the competency of teachers concerning the topic was examined and it was revealed that the teachers in both societies thought that they did not have adequate knowledge. It has been found out that teachers believed that they should be given more opportunities and that they wanted to transfer their competencies to students in similar patterns. In another question of the study, the manner with which Cypriot cultural values could make contribution to students in the course was searched. In this regard, it was expressed that teacher opinions were similar and that they believed that they would raise humanist and pacifist individuals.

As a result, this study found out that Turkish Cypriot and Greek Cypriot teachers had an optimistic viewpoint towards common cultural values of Cyprus and that they displayed the benefits and uses of including this topic especially in the content of art course. In addition, teachers stated that they did not cover the common cultural values of Cyprus in their classes before but that as a result of the positive developments in the island in the last 10 years they began to mention these topics verbally in the classroom environment. Some teachers emphasized that the topic should be included in the education curricula and that both societies should pay effort to put it into realization. It has been concluded that in relating the topic of common cultural values of Cyprus with art course curricula, there are more similarities between Turkish Cypriot and Greek Cypriot teachers than the disagreements.

\section{References}

1. Akhmetov, L. G., Badaev, V. S., Komelina, V. A., and Kuzmin, V. K., National arts and crafts in the content of art education of Russia. Review of European Studies, 7(1), 1, (2014).

2. Barkhordari, M., Nasrabadi, H. B., Heidari, M. H., \& Neyestani, M. R., The Importance of Art-Based Curriculum in Peace Education. Review of European Studies, 8 (4), 220, (2016).

3. Ballengee-Morris, C., \& Stuhr, P. L., Multicultural art and visual cultural education in a changing world. Art Education, 54(4), 6-13, (2001).

4. Bianchi, J., Intercultural identities: Addressing the global dimension through art education. International Journal of Art \& Design Education, 30(2), 279-292. (2011).

5. Cabedo-Mas, A., Nethsinghe, R., \& Forrest, D., The role of the arts in education for peacebuilding, diversity and intercultural understanding: A comparative study of educational policies in Australia and Spain. International Journal of Education \& the Arts, 18(11), (2017).

6. Duncum, P., A Critical Review of the Postmodern Implosion of Fine Art and Popular Visual Culture in Art Classrooms. United Kingdom: Palgrave Macmillan. (2017). 
7. Freedman, K., and Stuhr, P., Curriculum change for the 21 st century: Visual culture in art education. Handbook of research and policy in art education, 815$828,(2004)$.

8. LeVine, R. A., Culture, behavior, and personality: An introduction to the comparative study of psychosocial adaptation. Routledge, (2018).

9. Maziere, C., Artistic education in France: from the state to the classrooms' practices. International Journal of Education and the Arts, 16(23), (2015).

10. Miralay, F., "Comparison and Evaluation of Visual Arts Course Curricula in Turkish Republic of Northern Cyprus and Republic of Cyprus and a Draft Program proposal (Unpublished PhD Thesis) Near East University Education Sciences, (2018).

11. Moore, A., Teaching and learning: Pedagogy, curriculum and culture. Routledge, (2012).

12. Morley, S., Analytic and holistic approaches to fine art education: A comparative approach. Journal of Visual Art Practice, 13(2): 101-113, (2014).

13. Sacco, P., L., Culture 3.0: A new perspective for the EU 2014-2020 structural funds programming. OMC Working Group on Cultural and Creative Industries. (2011).

14. Şahin, D., \& Yağc1, M. M., The importance of art education in socialization process of individual. Journal of Life Sciences, 1(1), (2012).

15. United Nations Educational, Scientific and Cultural Organization (2009). Road Map for Arts Education. The World Conference on Arts Education: Building Creative Capacities for the 21st Century, Lisbon, 6-9 March 2006. 